\title{
Validating Sclerotinia sclerotiorum Apothecial Models to Predict Sclerotinia Stem Rot in Soybean (Glycine max) Fields
}

Jaime F. Willbur, Department of Plant Pathology, University of Wisconsin-Madison; Mamadou L. Fall, Saint-Jean-sur-Richelieu Research and Development Centre, Agriculture and Agri-Food Canada, Saint-Jean-sur-Richelieu, QC, Canada; and Department of Plant, Soil and Microbial Sciences, Michigan State University, East Lansing; Adam M. Byrne, Department of Plant, Soil and Microbial Sciences, Michigan State University; Scott A. Chapman, Megan M. McCaghey, and Brian D. Mueller, Department of Plant Pathology, University of WisconsinMadison; Roger Schmidt, Nutrient and Pest Management, University of Wisconsin-Madison; Martin I. Chilvers, Department of Plant, Soil and Microbial Sciences, Michigan State University; Daren S. Mueller, Department of Plant Pathology and Microbiology, Iowa State University, Ames; Mehdi Kabbage, Department of Plant Pathology, University of Wisconsin-Madison; Loren J. Giesler, Department of Plant Pathology, University of Nebraska-Lincoln; Shawn P. Conley, Department of Agronomy, University of Wisconsin-Madison; and Damon L. Smith, ${ }^{\dagger}$ Department of Plant Pathology, University of Wisconsin-Madison

\begin{abstract}
In soybean, Sclerotinia sclerotiorum apothecia are the sources of primary inoculum (ascospores) critical for Sclerotinia stem rot (SSR) development. We recently developed logistic regression models to predict the presence of apothecia in irrigated and nonirrigated soybean fields. In 2017, small-plot trials were established to validate two weather-based models (one for irrigated fields and one for nonirrigated fields) to predict SSR development. Additionally, apothecial scouting and disease monitoring were conducted in 60 commercial fields in three states between 2016 and 2017 to evaluate model accuracy across the growing region. Site-specific air temperature, relative humidity, and wind speed data were obtained through the Integrated Pest Information Platform for Extension

and Education (iPiPE) and Dark Sky weather networks. Across all locations, iPiPE-driven model predictions during the soybean flowering period (R1 to R4 growth stages) explained end-of-season disease observations with an accuracy of $81.8 \%$ using a probability action threshold of 35\%. Dark Sky data, incorporating bias corrections for weather variables, explained end-of-season disease observations with $87.9 \%$ accuracy (in 2017 commercial locations in Wisconsin) using a 40\% probability threshold. Overall, these validations indicate that these two weather-based apothecial models, using either weather data source, provide disease risk predictions that both reduce unnecessary chemical application and accurately advise applications at critical times.
\end{abstract}

Soybean (Glycine max (L.) Merr.) is one of the most economically important hosts impacted by Sclerotinia stem rot (SSR) (Peltier et al. 2012). Sclerotinia stem rot, caused by Sclerotinia sclerotiorum (Lib.) de Bary, continues to rank in the top 10 most destructive diseases of global soybean crops (Allen et al. 2017; Wrather et al. 2010). The development of $S$. sclerotiorum is favored by cool, moist conditions (Grau and Hartman 2015). In the north-central United States, these climatic conditions, combined with soybean growing practices geared toward high-yield environments, cause SSR to be particularly persistent and problematic in this region.

For soybean, apothecia that arise from soilborne sclerotia produce the primary source of inoculum, which are windborne ascospores that infect soybean flowers (Saharan and Mehta 2008). The simultaneous presence of apothecia during both soybean flowering and weather conditions favorable for infection and disease development

${ }^{\dagger}$ Corresponding author: Damon L. Smith; E-mail: damon.smith@wisc.edu

Funding: The integrated pest information platform for extension and education CAP is supported by the United States Department of Agriculture (USDA) National Institute of Food and Agriculture (NIFA) Agriculture and Food Research Initiative (AFRI) Competitive Grants Program Food Security Challenge Area Grant 2015-68004-23179. Additional generous support was provided by the USDA Hatch program, the University of WisconsinMadison Science and Medicine Graduate Research Scholars fellowship program, the Wisconsin Soybean Marketing Board, the Michigan Soybean Promotion Council, the North Central Soybean Research Program, and the United Soybean Board.

*The $\boldsymbol{e}$-Xtra logo stands for "electronic extra" and indicates that three supplementary tables are published online.

Accepted for publication 10 June 2018.

(c) 2018 The American Phytopathological Society is critical for the development of SSR that is typically observed later in the growing season (Abawi and Grogan 1975; Fall et al. 2018). Predictive models and risk algorithms are often used to assess the risk of Sclerotinia-induced disease development by considering these host-pathogen-environment factors, and to help farmers make management decisions (Clarkson et al. 2014; Foster et al. 2011; Harikrishnan and del Río 2008; Smith et al. 2007; Twengström et al. 1998). We have recently developed weather-based models to predict S. sclerotiorum apothecial development in soybean fields (Willbur et al. 2018). These models were subject to preliminary validations during development. However, additional validation across a larger geography is needed to determine their accuracy in predicting SSR disease levels later in the growing season.

Model validation is important to provide farmers with reliable management tools. Validation may include testing the models or algorithms at additional research and commercial sites over a larger growing area and outside of the locations where the model was developed (Foster et al. 2011). Other validations may investigate other aspects of risk algorithms such as the host susceptibility window, inoculum pressure, model cut-off probabilities, or action thresholds (Bondalapati and Stein 2010; Foster et al. 2011). Crowd-sourcing data over a wide region, through personal and social media communications, could be a powerful source of information for validations. Data from a variety of locations help to ensure that the models will work over the wide range of growing conditions and practices present in a region.

Additionally, for models to be adopted and implemented by farmers, the tools used to deliver these predictions should be easily accessible to farmers. Although site-specific data are readily available (Magarey et al. 2001), the risk algorithms often consider many factors which may complicate the delivery and use of these tools. Successful web-based systems have been developed for other diseases such as late blight in potato (Wharton et al. 2008). Ultimately, these models would be most useful to farmers if they could be repeatedly accessed at site-specific field locations over an entire growing season. Based on these predictions, farmers could then make "real-time" 
management decisions that are not impeded by reliance of information released through researchers or cooperative extension personnel.

The objectives of this research were to (i) validate two weatherbased apothecial prediction models throughout the north-central soybean-growing region in both research and commercial fields, (ii) evaluate fungicide programs as a part of model implementation, (iii) identify the host susceptibility period for incorporation into the model algorithm, and (iv) determine appropriate action thresholds (i.e., when to apply fungicide sprays) for incorporation of these models in an effective integrated management system.

\section{Materials and Methods}

Evaluation of fungicide efficacy and timing for model validation in research trials. Iowa. In 2017, two validation trials were monitored near Manilla and Nashua, IA (Table 1). In each location, an SSR-susceptible soybean cultivar, Pioneer 25T51R (Pioneer 2017), was planted on 13 May at 370,000 seeds ha ${ }^{-1}$. The plots were $3.0 \mathrm{~m}$ wide by $5.3 \mathrm{~m}$ long and contained four rows planted at a $0.76-$ $\mathrm{m}$ row spacing. These trials were used to evaluate 11 different fungicide treatments: boscalid (Endura; BASF, Research Triangle Park, NC) applied at R1 (beginning flower), 7 days after beginning flowering (R1) (approximately R2, full flower), 14 days after R1 (approximately R3, beginning pod), or 21 days after R1 (approximately R4, full pod); picoxystrobin (Aproach; DuPont, Wilmington, DE) applied at R1, R2, beginning pod (R3), or R1 then R3; lactofen (Cobra; Valent U.S.A., Walnut Creek, CA) applied at V5 or at V5 followed by picoxystrobin applied at R1; and a nontreated check (Table 2). These treatments were replicated four times and arranged in a randomized complete block design (RCBD) at each location, for a total of 88 plots. These trials were nonirrigated and only natural inoculum was relied upon for infection by S. sclerotiorum. The flowering period was approximately 14 days for all research trials in Iowa, and also those in Michigan and Wisconsin.

Apothecia were counted in 0.76-by-0.76-m squares placed in three arbitrary locations of each nontreated check plot (four plots per trial). In Manilla, apothecial scouting was conducted on 5 days (6 June, 11 July, 17 July, 24 July, and 31 July) which began prior to R1 and continued through the R3 growth stage. In Nashua, scouting was conducted on 2 days (25 July and 3 August) which began 14 days after R1 and continued through R3. Number of apothecia observed in each square was recorded for each nontreated plot for a total of 60 observations in Manilla and 24 observations in Nashua $(n=84$ total Iowa observations).

SSR incidence or severity was evaluated at the full seed (R6) growth stage. Disease incidence (DI) was determined by recording the number of symptomatic plants out of 30 arbitrarily selected plants in the center two rows of each plot and converting to a percentage. Disease severity (DS) was determined by rating these 30 plants on a 0 -to- 3 scale, where $0=$ no disease, $1=$ disease only on the petioles or secondary stems, $2=$ disease on but not girdling the main stem, and $3=$ disease girdling the main stem, resulting in plant wilt or death (Grau et al. 1982). Severity ratings of symptomatic plants were averaged, divided by 3 , and multiplied by the percent DI to obtain the disease severity index (DIX) value.
For Iowa, and all research sites in Michigan and Wisconsin, yield data were collected using a small-plot combine to harvest the center two rows of each plot. Yield data were adjusted to $13 \%$ moisture. DI or DIX values and yield data were used to evaluate fungicide treatment efficacy. DI values were also used in site-specific validations of model predictions over the entire season.

Michigan. In 2017, model validation was conducted by researchers at Michigan State University in small plot trials at the Montcalm Research Center in Montcalm, MI (Table 1). These trials were conducted in a similar fashion to that described above. However, soybeans were planted at two row spacings, 0.76 and $0.38 \mathrm{~m}$, on 19 May and 22 May, respectively. The moderately SSR-tolerant soybean cultivar Asgrow AG2535 (Monsanto 2017) was planted at a population of 400,000 plants ha ${ }^{-1}$. Eleven fungicide and timing treatments, similar to those tested in Iowa, were evaluated at both row spacings (Table 2). These treatments were replicated five times and arranged in an RCBD at each row spacing, for a total of 110 plots.

Four additional site areas were used for apothecial monitoring. Within each row spacing, two sampling sites were designated and 4 plots were constructed within each site, for a total of 16 plots. The plots were the same size as the Michigan research trial plots previously mentioned. The cultivar AG2535 was planted in all of the plots at the $0.38-\mathrm{m}$ spacing. The plots at $0.76-\mathrm{m}$ spacing were planted with two additional, undisclosed susceptible soybean cultivars. No fungicide treatments were applied to these areas. These trials were overhead irrigated and relied on natural sources of inoculum.

Within each apothecial monitoring plot (not in the fungicide validation trial), observations were recorded in four arbitrarily selected 0.74-by-0.74-m squares. In $0.38-\mathrm{m}$ row spacing plots, data were collected between the third and fifth row. In the $0.76-\mathrm{m}$ row spacing, the data were collected between the center rows (second and third). Thirteen days of observations were collected from apothecial monitoring plots, and numbers of apothecia were recorded for each sampling of the four locations in each of the 16 plots. Observations were collected every 3 to 6 days beginning 20 July and continuing to 1 September ( $n=832$ total Michigan observations).

SSR incidence and severity were evaluated in the fungicide validation trials on 19 September (not in the apothecial monitoring sites). DI was determined by recording the number of symptomatic plants out of 40 arbitrarily selected plants in the center two rows of each plot and converting to a percentage. DS was determined by rating these 40 plants on the previously described 0 -to-3 scale. Severity ratings of symptomatic plants were averaged, divided by 3 , and multiplied by the percent DI to obtain the DIX value.

Wisconsin. In 2017, research trials used for model validations were conducted by researchers at University of Wisconsin-Madison agricultural research stations (ARS) in Arlington and Hancock, WI (Table 1). Trials were planted using a $0.76-\mathrm{m}$ row spacing at a population density of 350,000 plants $\mathrm{ha}^{-1}$. The soybean cultivar Asgrow AG2031, which has shown greenhouse susceptibility and moderate field resistance (data not presented), was planted in four-row plots that were $3.0 \mathrm{~m}$ wide by $6.1 \mathrm{~m}$ long.

In Arlington, the trial was planted on 30 May and used to evaluate seven fungicide treatments (Table 2), including a nontreated control

Table 1. Research trial locations and GPS coordinates (Coord.), including information for cultivar, irrigation (IR), row spacing (Row), number of plots per trial (Plots), number of squares scouted per plot (Sq), number of days observations were collected (D), and total number of observations $(N)$, used to validate apothecial risk models during a 14-day flowering period at all locations in 2017

\begin{tabular}{|c|c|c|c|c|c|c|c|c|c|c|c|}
\hline Field ID & State & Location & County & Coord. & Cultivar $^{\mathbf{z}}$ & IR & Row (m) & Plots & Sq & D & $N$ \\
\hline R17-I1 & IA & Manilla & Shelby & $41.8495,-95.1751$ & P25T51R & $\mathrm{N}$ & 0.76 & 4 & 3 & 5 & 60 \\
\hline R17-I2 & IA & Nashua & Black Hawk & $42.9382,-92.5696$ & P25T51R & $\mathrm{N}$ & 0.76 & 4 & 3 & 2 & 24 \\
\hline R17-M1 & MI & Montcalm & Montcalm & $43.3525,-85.1788$ & AG2535 & $\mathrm{Y}$ & 0.76 & 55 & $\ldots$ & $\ldots$ & $\ldots$ \\
\hline R17-M2 & MI & Montcalm & Montcalm & $43.3525,-85.1788$ & AG2535 & $\mathrm{Y}$ & 0.38 & 55 & $\ldots$ & $\ldots$ & $\ldots$ \\
\hline R17-M3 & MI & Montcalm & Montcalm & $43.3525,-85.1788$ & AG2535 & $\mathrm{Y}$ & 0.76 & 8 & 4 & 13 & 416 \\
\hline R17-M4 & MI & Montcalm & Montcalm & $43.3525,-85.1788$ & AG2535 & $\mathrm{Y}$ & 0.38 & 8 & 4 & 13 & 416 \\
\hline R17-W1 & WI & Arlington & Dane & $43.3266,-89.3271$ & AG2031 & $\mathrm{N}$ & 0.76 & 28 & 3 & 4 & 336 \\
\hline R17-W2 & WI & Hancock & Waushara & $44.1219,-89.5379$ & AG2031 & $\mathrm{Y}$ & 0.76 & 16 & 3 & 4 & 192 \\
\hline
\end{tabular}

${ }^{\mathrm{z}}$ Abbreviations within cultivar names are as follows: $\mathrm{P}=$ Pioneer Brand and $\mathrm{AG}=$ Asgrow Brand. 
as well as boscalid and picoxystrobin treatments applied according to plant phenology or using the newly developed models to schedule fungicide applications. The treatments were replicated four times and arranged in an RCBD for a total of 28 plots. The trial was nonirrigated and only natural sources of inoculum were available for S. sclerotiorum infection.

In Hancock, the trial was planted on 25 May and used to evaluate four fungicide treatments (Table 2), including a nontreated control and three different treatments of picoxystrobin applied at either phenology- or model-based timings. These treatments were evaluated in an RCBD with four replications, for a total of 16 plots. This trial was overhead irrigated to promote SSR development. Soybean trials were conducted in areas previously planted with sunflower, which had been inoculated with $S$. sclerotiorum to increase available inoculum load in the soil.
Apothecia were counted in three 0.76-by-0.76-m squares in the center two rows of each plot. Weekly scouting was conducted on 4 days between the R1 and R4 growth stages. In Arlington, scouting was conducted on 12 July, 18 July, 27 July, and 3 August. The Hancock trial was scouted on 13 July, 19 July, 26 July, and 3 August. In Arlington, 336 sample observations were recorded; in Hancock, 192 sample observations were recorded $(n=528$ total Wisconsin observations).

SSR incidence, severity, and DIX data were collected at R6 or R7 (beginning maturity). Severity data were collected according to the protocols previously described. The true DI was collected by counting the total number of symptomatic plants in the center two rows and converting to a percentage of the total stand count. The DIX was calculated as previously described using the true DI and average DS of symptomatic plants.

Table 2. Fungicide treatments, including various active ingredients (AI) and application timings, evaluated in Iowa, Michigan, and Wisconsin research trials used for model validation, 2017

\begin{tabular}{|c|c|c|c|c|c|c|}
\hline Location, treatment & Product & AI & Rate/ha & Application timing ${ }^{x}$ & Growth stage $^{y}$ & Date of application \\
\hline \multicolumn{7}{|c|}{ Iowa: Manilla and Nashua } \\
\hline 1 & Nontreated & $\ldots$ & $\ldots$ & $\ldots$ & $\ldots$ & $\ldots$ \\
\hline 2 & Cobra & Lactofen & $438.5 \mathrm{ml}$ & V5 & V5 & 6 July \\
\hline 3 & Endura & Boscalid & $560.4 \mathrm{~g}$ & $\mathrm{R} 1$ & $\mathrm{R} 1$ & 11 July \\
\hline 4 & Endura & Boscalid & $560.4 \mathrm{~g}$ & 7 days post-R1 & $\mathrm{R} 2$ & 18 July \\
\hline 5 & Endura & Boscalid & $560.4 \mathrm{~g}$ & 14 days post-R1 & $\mathrm{R} 3$ & 25 July \\
\hline 6 & Endura & Boscalid & $560.4 \mathrm{~g}$ & 21 days post-R1 & $\mathrm{R} 4$ & 1 August \\
\hline 7 & Aproach & Picoxystrobin & $657.7 \mathrm{ml}$ & $\mathrm{R} 1$ & $\mathrm{R} 1$ & 11 July \\
\hline 8 & Aproach & Picoxystrobin & $657.7 \mathrm{ml}$ & 7 days post-R1 & $\mathrm{R} 2$ & 18 July \\
\hline 9 & Aproach & Picoxystrobin & $657.7 \mathrm{ml}$ & 14 days post-R1 & $\mathrm{R} 3$ & 25 July \\
\hline \multirow[t]{2}{*}{10} & Aproach & Picoxystrobin & $657.7 \mathrm{ml}$ & $\mathrm{R} 1 \mathrm{fb}$ & $\mathrm{R} 1$ & 11 July \\
\hline & Aproach & Picoxystrobin & $657.7 \mathrm{ml}$ & 14 days post-R1 & $\mathrm{R} 3$ & 25 July \\
\hline \multirow[t]{2}{*}{11} & Cobra & Lactofen & $657.7 \mathrm{ml}$ & $\mathrm{V} 5 \mathrm{fb}$ & V5 & 6 July \\
\hline & Aproach & Picoxystrobin & $657.7 \mathrm{ml}$ & $\mathrm{R} 1$ & $\mathrm{R} 1$ & 11 July \\
\hline \multicolumn{7}{|l|}{ Michigan: Montcalm } \\
\hline 1 & Nontreated & $\ldots$ & $\ldots$ & $\ldots$ & $\ldots$ & $\ldots$ \\
\hline 2 & Cobra & Lactofen & $438.5 \mathrm{ml}$ & V5 & V5 & 6 July \\
\hline 3 & Endura & Boscalid & $560.4 \mathrm{~g}$ & $\mathrm{R} 1$ & $\mathrm{R} 1$ & 17 July \\
\hline 4 & Endura & Boscalid & $560.4 \mathrm{~g}$ & 7 days post-R1 & $\mathrm{R} 2$ & 24 July \\
\hline 5 & Endura & Boscalid & $560.4 \mathrm{~g}$ & 14 days post-R1 & R3 & 24 July \\
\hline 6 & Endura & Boscalid & $560.4 \mathrm{~g}$ & 21 days post-R 1 & $\mathrm{R} 4$ & 31 July \\
\hline 7 & Aproach & Picoxystrobin & $657.7 \mathrm{ml}$ & $\mathrm{R} 1$ & $\mathrm{R} 1$ & 17 July \\
\hline 8 & Aproach & Picoxystrobin & $657.7 \mathrm{ml}$ & 7 days post-R1 & $\mathrm{R} 2$ & 24 July \\
\hline 9 & Aproach & Picoxystrobin & $657.7 \mathrm{ml}$ & 14 days post-R 1 & R3 & 24 July \\
\hline \multirow[t]{2}{*}{10} & Aproach & Picoxystrobin & $657.7 \mathrm{ml}$ & $\mathrm{R} 1 \mathrm{fb}$ & $\mathrm{R} 1$ & 17 July \\
\hline & Aproach & Picoxystrobin & $657.7 \mathrm{ml}$ & 14 days post-R1 & R3 & 24 July \\
\hline \multirow[t]{2}{*}{11} & Cobra & Lactofen & $438.5 \mathrm{ml}$ & $\mathrm{V} 5 \mathrm{fb}$ & V5 & 6 July \\
\hline & Aproach & Picoxystrobin & $657.7 \mathrm{ml}$ & $\mathrm{R} 1$ & $\mathrm{R} 1$ & 17 July \\
\hline \multicolumn{7}{|l|}{ Wisconsin: Arlington ${ }^{z}$} \\
\hline 1 & Nontreated & $\ldots$ & $\ldots$ & $\ldots$ & $\ldots$ & $\ldots$ \\
\hline \multirow[t]{2}{*}{2} & Aproach & Picoxystrobin & $657.7 \mathrm{ml}$ & $\mathrm{R} 1 \mathrm{fb}$ & $\mathrm{R} 1$ & 14 July \\
\hline & Aproach & Picoxystrobin & $657.7 \mathrm{ml}$ & R3 & R3 & 28 July \\
\hline 3 & Endura & Boscalid & $560.4 \mathrm{~g}$ & $\mathrm{R} 1$ & $\mathrm{R} 1$ & 14 July \\
\hline \multirow[t]{2}{*}{4} & Aproach & Picoxystrobin & $657.7 \mathrm{ml}$ & Threshold $1 \mathrm{fb}$ & $\mathrm{R} 1$ & 14 July \\
\hline & Aproach & Picoxystrobin & $657.7 \mathrm{ml}$ & Threshold 1 & R3 & 28 July \\
\hline 5 & Aproach & Picoxystrobin & $657.7 \mathrm{ml}$ & Threshold 2 & - & - \\
\hline \multirow[t]{2}{*}{6} & Endura & Boscalid & $560.4 \mathrm{~g}$ & Threshold $1 \mathrm{fb}$ & $\mathrm{R} 1$ & 14 July \\
\hline & Endura & Boscalid & $560.4 \mathrm{~g}$ & Threshold 1 & $\mathrm{R} 3$ & 28 July \\
\hline 7 & Endura & Boscalid & $560.4 \mathrm{~g}$ & Threshold 2 & - & - \\
\hline \multicolumn{7}{|l|}{ Wisconsin: Hancock ${ }^{\mathrm{z}}$} \\
\hline 1 & Nontreated & $\ldots$ & $\ldots$ & $\ldots$ & $\ldots$ & $\ldots$ \\
\hline \multirow[t]{2}{*}{2} & Aproach & Picoxystrobin & $657.7 \mathrm{ml}$ & $\mathrm{R} 1 \mathrm{fb}$ & R1 & 14 July \\
\hline & Aproach & Picoxystrobin & $657.7 \mathrm{ml}$ & $\mathrm{R} 3$ & R3 & 28 July \\
\hline \multirow[t]{2}{*}{3} & Aproach & Picoxystrobin & $657.7 \mathrm{ml}$ & Threshold $1 \mathrm{fb}$ & $\mathrm{R} 1$ & 14 July \\
\hline & Aproach & Picoxystrobin & $657.7 \mathrm{ml}$ & Threshold 1 & $\mathrm{R} 3$ & 28 July \\
\hline 4 & Aproach & Picoxystrobin & $657.7 \mathrm{ml}$ & Threshold 2 & R3 & 28 July \\
\hline
\end{tabular}

${ }^{\mathrm{x}}$ Sequential application timings were made in some instances and are indicated by $\mathrm{fb}=$ followed by.

y Growth stages: V5 (fifth trifoliate), R1 (beginning flower), R2 (full flower), R3 (beginning pod), and R4 (full pod).

${ }^{\mathrm{z}}$ In Wisconsin trials, phenology-based fungicide programs were compared with programs applied between the R1 and R3 growth stages when risk was above action threshold 1, equal to $15 \%$, or action threshold 2, equal to $30 \%$. In some cases, low risk resulted in no applications, designated by the symbol -. 
Commercial fields used for model validations. Wisconsin. In 2016, 22 commercial fields were scouted for apothecia and monitored for disease development. Fields were located throughout the state. Apothecial scouting occurred between the R1 to R4 growth stages between 14 July and 1 August. Observations were made in 10 to 30 sites, at intervals of 50 to 100 paces (or approximately 38 to $76 \mathrm{~m}$ ), depending on the size of the field, using a W or Z sampling pattern. At each sampling site, a 0.76-by-0.76-m square area was scouted for apothecia. Number of apothecia per sampling square was recorded and converted to binary presence or absence data for each site. Soybean cultivar, row width, irrigation, canopy closure, SSR history, typical crop rotation, and fungicide applications were noted at the time of the visit (Supplementary Table S1). In total, 397 individual site observations were collected in Wisconsin.

Follow-up visits were conducted between the R5 to R7 growth stages between 8 August and 14 September. Observations were made at 10 to 21 sites, at intervals of 38 to $76 \mathrm{~m}$, using a W or Z sampling pattern. At each site within a field, a 1.0-m length in each of two rows (for a total of $2.0 \mathrm{~m}$ ) was rated for DI (total symptomatic plants) and DS (30 plants per site were rated using the previously described scale). The DI and DS scores were used to calculate the DIX; the field DI and DIX values were averaged for each field location. The total number of plants in the $2.0-\mathrm{m}$ stand was also recorded for two to four sites within the field to estimate the total population of plants per hectare. In total, 343 disease observations were made in Wisconsin.

In 2017, 32 commercial fields were monitored for apothecial and SSR development. Again, fields were representative of the entire soybean-growing region. Apothecial scouting occurred between the R1 to R4 growth stages between 13 July and 3 August. Observations were made in 20 to 23 sites, typically at intervals of 100 paces (or $76 \mathrm{~m}$ ), depending on the size of the field, using the previously described pattern. A 0.76-by-0.76-m square area was scouted for apothecia at each sampling site. Data were collected as in 2016. In total, 608 apothecial observations were recorded in Wisconsin farmers' fields.

Follow-up visits were conducted during the R5 to R7 growth stages between 18 August and 12 September. Observations were collected at 20 to 24 sites, at intervals of $76 \mathrm{~m}$, using a W or Z sampling pattern. At each site within a field, a 1.0-m length in each of two rows (for a total of $2.0 \mathrm{~m}$ ) was again rated for DI and DS. The field DI, DIX, and population were recorded for each field location and used in model validations. In total, 633 disease observations were made in farmers' fields in 2017.

Michigan. In 2017, three additional commercial fields were used in model validations. The location, cultivar, row width, irrigation, SSR history, and estimated R1 and R3 dates were recorded for each field location. SSR incidence was estimated for these fields; however, no individual site data within the field were collected and no apothecial scouting was conducted.

Nebraska. Two commercial fields were scouted for apothecia and disease in 2017. Observations were collected in 20 sites throughout the field, at intervals of 50 to 100 paces ( 38 to $76 \mathrm{~m}$ ), depending on the size of the field, using a $\mathrm{W}$ or $\mathrm{Z}$ sampling pattern. SSR ratings were collected on 24 August in Scribner and 29 August in the Ord location. The ratings were taken as previously described in a $1.0-\mathrm{m}$ length of row in two rows and incidence and severity data were collected. Data were used to calculate the average field DI and DIX, which were used in model validations. The soybean cultivar, row spacing, irrigation, SSR history, crop rotation, fungicide applications, and estimated R1 and R3 dates were recorded for both locations.

Validation of apothecial model accuracy in research and commercial fields. Integrated Pest Information Platform for Extension and Education weather-based probability predictions. Through cooperation with the Integrated Pest Information Platform for Extension and Education (iPiPE) project, gridded weather data at a 5-km resolution were obtained for each research and commercial validation site (Isard et al. 2015). The high-resolution real-time mesoscale analysis (RTMA) data (Benjamin et al. 2007) were supplied by ZedX, Inc. (Bellefonte, PA). Data were sourced from the National Oceanic and Atmospheric Administration National Centers for Environmental Prediction. As in the study by Willbur et al. (2018), site- specific weather data were generated for each site using GPS coordinates. Hourly estimates of air temperature (AT), relative humidity $(\mathrm{RH})$, and wind speed (WS) were used to generate daily maximum values of these weather variables; daily maximums were then used to calculate 30-day moving averages of maximum AT, RH, and WS (MaxAT $T_{30 M A}, M^{2} R_{30 M A}$, or MaxWS ${ }_{30 M A}$, respectively). Moving averages were used in previously developed logistic regression models, either in the nonirrigated model:

$$
\operatorname{Logit}(\mu)=-0.47\left(\operatorname{MaxAT}_{30 M A}\right)-1.01\left(\operatorname{MaxWS}_{30 M A}\right)+16.65
$$

or the irrigated model:

$$
\begin{aligned}
\operatorname{Logit}(\mu)= & -2.38(\text { Row })+0.65\left(\operatorname{MaxAT}_{30 M A}\right) \\
& +0.38\left(\operatorname{MaxRH}_{30 M A}\right)-52.65
\end{aligned}
$$

where the row width variable was equal to 0 or 1 when the row spacing was 0.38 or $0.76 \mathrm{~m}$, respectively (Willbur et al. 2018). For each validation site, the probability of apothecial presence was generated using the following calculation with the appropriate model logit equation:

$$
\text { Probability }=\frac{e^{\operatorname{logit}(\mu)}}{\left(1+e^{\log i t(\mu)}\right)}
$$

Validation of model accuracy in research trials. The accuracy of the apothecial probability models presented in equations 1 and 2 was evaluated at all research locations. At each site, two binary DI variables were constructed: DI5 and DI10 (in-field DI thresholds of 5 and $10 \%$, respectively). If the mean DI in the nontreated plots was $\geq 5 \%$, then DI5 was 1 . If the mean DI was $<5 \%$, then DI5 was 0 . Likewise, the DI10 variable was set to 1 if the mean DI in the nontreated plots was $\geq 10 \%$ and 0 if $<10 \%$. These thresholds reflect conservative estimations of DI which correspond to farmer impressions of disease levels that require management. For each site, the apothecial model probability (calculated in equation 3) was monitored throughout the growing season at estimated probability thresholds of 30,35 , and $40 \%$. If the probability was greater than the probability threshold during the R1 to R3 period, then the site was given a 1 to indicate that apothecia were likely present. If the calculated probability was less than the prediction threshold during this flowering period, then the site was assigned a 0 to indicate that probability was low. If there was agreement between disease observations and probability (during the flowering period), then a model success (1) was recorded. If there was disagreement between these observations, then a model failure (0) was recorded. Model accuracy was calculated as the percentage of successes out of the total number of site observations and was calculated for all probability thresholds $(30,35$, and $40 \%$ ) using both DI5 and DI10 observations. Type 1 (overprediction) or 2 (under-prediction) errors were also recorded for each model failure. Six research trial sites where disease observations were recorded were used to validate apothecial model accuracy.

Validation of model accuracy in commercial fields. For each field, the binary DI variables DI5 and DI10 were generated. Probability thresholds of 30,35 , and $40 \%$ were again used to determine the risk of disease development ( 1 or 0 ) during the R1 to R3 period. Agreement between model observations and end-of-season SSR observations were used to determine whether the model at a site was a success (1) or failure (0). Model accuracy, or the percentage of successes out of the total number of sites, was calculated for all probability thresholds $(30,35$, and $40 \%)$ using both DI5 and DI10 thresholds. Once again, type 1 (over-prediction) or 2 (underprediction) errors were recorded for each model failure. Accuracy was evaluated at 22 commercial sites in 2016 and 38 sites in 2017.

Dark Sky weather-based probability predictions. Hyperlocal hourly weather data for AT, RH, and WS were also obtained using the Dark Sky weather data network (Dark Sky Company, Cambridge, MA), accessible through darksky.net. These data were used to generate 30-day moving averages of weather variables. Moving averages were used in equations 1,2 , and 3 to generate apothecial 
presence probabilities. These weather data were compared with highresolution RTMA weather data (sourced from iPiPE) from University of Wisconsin-Madison research sites at the West Madison ARS in 2015, the Arlington ARS in 2016 and 2017, and the Hancock ARS in 2017 (Willbur et al. 2018). These data were also used in correlation analyses with on-site data collected using a Campbell Scientific (Logan, UT) weather station and sensors (Willbur et al. 2018). The weather station and sensors described by Willbur et al. (2018) were used at the 2017 Arlington site (Table 1) and replicated at the 2017 Hancock site (Table 1). As an additional test of Dark Sky weather data accuracy, data (corrected with the identified biases) were also used to validate apothecial model accuracy in 33 Wisconsin commercial sites.

Statistical analysis. All statistical analyses were conducted in SAS (v 9.4; SAS Institute, Cary, NC). Efficacy evaluations of fungicides and timings were analyzed using an analysis of variance in a generalized linear mixed-model (GLIMMIX) procedure. Response variables DI, DIX, and yield were evaluated using treatment as a fixed effect. The normal distribution was used, and confirmed using diagnostic plots, and the Kenward-Roger degrees of freedom approximation was used. Replicate or block was considered a random effect in all efficacy evaluations. Differences between treatment means were evaluated using Fisher's least significant different at the $\alpha=0.05$ significance level. If the treatment effect was significant, then all pairwise comparisons were considered using the "mult" macro (Piepho 2004).
Comparisons of hourly Dark Sky, iPiPE, and on-site weather data were conducted using the Pearson correlation analyses with the CORR procedure. Bias coefficients were calculated from the mean difference (generated using PROC MEANS) between hourly RTMA data or on-site Campbell weather station data and Dark Sky data, where bias coefficient = hourly Dark Sky RTMA or on-site data hourly Dark Sky data (Charney et al. 2013). These bias coefficients were used to correct Dark Sky data for further model validations (Dark Sky moving average + Bias + standard deviation). As in Willbur et al. (2018), Lin's concordance analyses (Lin 1989) were conducted using code available through the Pennsylvania State University, Eberly College of Science (Lengerich 2017).

\section{Results}

Evaluation of fungicide efficacy and timing for model validation in research and commercial fields. In Iowa in 2017, no significant differences $(P>0.05)$ between treatments were detected for DI, DIX, or yield in Manilla (Table 3) or Nashua (Table 4) trials. The apothecial probability during the R1 to R4 period was correspondingly low $(<10 \%)$ for nonirrigated fields (Fig. 1A and B).

Differences were detected in yield $(P<0.001)$ and DIX $(P<0.05)$ in the trials in Montcalm, MI (Table 5) at the 0.76- and 0.38-m row spacings, respectively. At the $0.76-\mathrm{m}$ row width, the nontreated plots resulted in a yield of $3,284.4 \mathrm{~kg} \mathrm{ha}^{-1}$, and applications of Endura at $\mathrm{R} 2, \mathrm{R} 3$, and R4 or Aproach at R3 resulted in the greatest yield $\left(3,750.8\right.$ to $\left.4,412.5 \mathrm{~kg} \mathrm{ha}^{-1}\right)$ despite high DI. In the trial at $0.38-\mathrm{m}$

Table 3. Validation of various fungicide products and application timings, evaluated using disease incidence (DI) and yield, in Manilla, IA 2017

\begin{tabular}{|c|c|c|c|c|c|}
\hline Treatment & Product & Rate/ha & Application timingy & DI $(\%)$ & Yield (kg/ha) \\
\hline 1 & Nontreated & $\ldots$ & $\ldots$ & 1.3 & $4,626.7$ \\
\hline 2 & Cobra & $438.5 \mathrm{ml}$ & V5 & 4.0 & $4,834.9$ \\
\hline 3 & Endura & $560.4 \mathrm{~g}$ & $\mathrm{R} 1$ & 1.3 & $4,755.4$ \\
\hline 4 & Endura & $560.4 \mathrm{~g}$ & $\mathrm{R} 2$ & 3.3 & $4,833.4$ \\
\hline 5 & Endura & $560.4 \mathrm{~g}$ & R3 & 2.7 & $4,997.3$ \\
\hline 6 & Endura & $560.4 \mathrm{~g}$ & R4 & 2.0 & $4,690.5$ \\
\hline 7 & Aproach & $657.7 \mathrm{ml}$ & R1 & 0.0 & $4,626.0$ \\
\hline 8 & Aproach & $657.7 \mathrm{ml}$ & $\mathrm{R} 2$ & 2.0 & $4,531.5$ \\
\hline 9 & Aproach & $657.7 \mathrm{ml}$ & R3 & 0.7 & $4,740.8$ \\
\hline \multirow[t]{2}{*}{10} & Aproach & $657.7 \mathrm{ml}$ & $\mathrm{R} 1 \mathrm{fb}$ & 4.0 & $4,706.5$ \\
\hline & Aproach & $657.7 \mathrm{ml}$ & R3 & $\ldots$ & $\ldots$ \\
\hline \multirow[t]{2}{*}{11} & Cobra & $438.5 \mathrm{ml}$ & $\mathrm{V} 5 \mathrm{fb}$ & 0.7 & $4,524.1$ \\
\hline & Aproach & $657.7 \mathrm{ml}$ & $\mathrm{R} 1$ & $\ldots$ & $\ldots$ \\
\hline$F$ & $\ldots$ & $\ldots$ & $\ldots$ & 1.13 & 0.7 \\
\hline$P$ value ${ }^{\mathrm{z}}$ & $\cdots$ & $\cdots$ & $\cdots$ & 0.36 & 0.72 \\
\hline
\end{tabular}

y Sequential application timings were made in some instances and are indicated by $\mathrm{fb}=$ followed by.

${ }^{z}$ Significance level: $\alpha=0.05$.

Table 4. Validation of various fungicide products and application timings, evaluated using disease incidence (DI), disease severity index (DIX), and yield, in Nashua, IA 2017

\begin{tabular}{|c|c|c|c|c|c|c|}
\hline Treatment & Product & Rate/ha & Application timingy & DI (\%) & DIX (\%) & Yield (kg/ha) \\
\hline 1 & Nontreated & $\ldots$ & $\ldots$ & 5.0 & 3.9 & $3,978.7$ \\
\hline 2 & Cobra & $438.5 \mathrm{ml}$ & V5 & 12.5 & 11.7 & $3,911.0$ \\
\hline 3 & Endura & $560.4 \mathrm{~g}$ & $\mathrm{R} 1$ & 15.0 & 13.6 & $3,357.3$ \\
\hline 4 & Endura & $560.4 \mathrm{~g}$ & $\mathrm{R} 2$ & 6.7 & 6.1 & $3,810.0$ \\
\hline 5 & Endura & $560.4 \mathrm{~g}$ & R3 & 13.3 & 13.1 & $3,946.0$ \\
\hline 6 & Endura & $560.4 \mathrm{~g}$ & $\mathrm{R} 4$ & 14.2 & 13.3 & $3,648.6$ \\
\hline 7 & Aproach & $657.7 \mathrm{ml}$ & $\mathrm{R} 1$ & 12.5 & 11.9 & $3,888.7$ \\
\hline 8 & Aproach & $657.7 \mathrm{ml}$ & $\mathrm{R} 2$ & 12.5 & 12.2 & $3,578.7$ \\
\hline 9 & Aproach & $657.7 \mathrm{ml}$ & $\mathrm{R} 3$ & 8.3 & 7.2 & $3,971.9$ \\
\hline \multirow[t]{2}{*}{10} & Aproach & $657.7 \mathrm{ml}$ & $\mathrm{R} 1 \mathrm{fb}$ & 5.0 & 4.5 & $3,662.0$ \\
\hline & Aproach & $657.7 \mathrm{ml}$ & $\mathrm{R} 3$ & $\ldots$ & $\ldots$ & $\ldots$ \\
\hline \multirow[t]{2}{*}{11} & Cobra & $438.5 \mathrm{ml}$ & V5 fb & 15.8 & 15.0 & $3,535.2$ \\
\hline & Aproach & $657.7 \mathrm{ml}$ & $\mathrm{R} 1$ & $\ldots$ & $\ldots$ & $\ldots$ \\
\hline$F$ & $\ldots$ & $\ldots$ & $\ldots$ & 0.86 & 0.95 & 1.25 \\
\hline$P$ value ${ }^{\mathrm{z}}$ & $\ldots$ & $\ldots$ & $\ldots$ & 0.58 & 0.50 & 0.30 \\
\hline
\end{tabular}

y Sequential application timings were made in some instances and are indicated by $\mathrm{fb}=$ followed by.

${ }^{\mathrm{z}}$ Significance level: $\alpha=0.05$. 
row spacing, the nontreated plots had 70.3\% DIX and all Endura applications or Aproach applied at R3 resulted in the lowest DIX (43.3 to $62.2 \%$ ). The corresponding model probabilities for Montcalm (Fig. 1C) indicated that the probability in irrigated $0.38-\mathrm{m}$ fields was $>30 \%$ between R1 and R4. Conversely, the probability in irrigated $0.76-\mathrm{m}$ fields was $>5 \%$ at R1 and reached $10 \%$ near R2.

No significant differences between true DI, DIX, or yield of different treatments $(P>0.05)$ were detected at trials in Arlington (Table 6) or Hancock (Table 7). The nonirrigated Arlington validation site had low levels of disease (2.0\% DI and 1.5\% DIX in nontreated plots). Although not significantly different, boscalid treatments resulted in lower DI and DIX and greater yield than those of the nontreated control or picoxystrobin treatments (Table 6). At this nonirrigated site, slightly lower disease levels and higher yields were achieved using a $15 \%$ probability action threshold; however, neither was significantly different from the nontreated control. In Hancock trials, DI in the nontreated plots was $17.7 \%$ and yield was $3,099.3 \mathrm{~kg} \mathrm{ha}^{-1}$ (Table 7). Again, although not significant, treatments applied at a probability action threshold of $15 \%$ resulted in lower DI and DIX than those applied at a $30 \%$ threshold. No notable trends were observed in yield of different treatments at Hancock. The model probabilities for the nonirrigated Arlington site (Fig. 1D) indicated low probability of apothecial presence $(<20 \%)$ during the R1 to R3 period; the predicted probability at the irrigated Hancock site (Fig.
1E) indicated that apothecial presence was likely, with a probability greater than $25 \%$ near the R3 growth stage.

Apothecia were observed in five of the six research trials used to validate model accuracy (Supplementary Table S2). Three sites had SSR above the DI thresholds (5 and 10\%) previously established and three sites had low SSR levels, below the DI thresholds. For all three probability thresholds $(30,35$, and $40 \%)$, as many as five of six research sites were recorded as model successes. Model failure was typically due to type 2 error, or failure of the model to predict presence of apothecia where disease was present.

In commercial fields, apothecia were only detected in two of the fields in 2016 (Supplementary Table S3). No apothecia were detected in 2017 farmer-fields. Mean disease observations ranged from 0.0 to $40.2 \%$ in 2016 and 0.0 to $80 \%$ (the maximum was based on a single visual field estimate) in 2017. In 2016, 18 successes out of 22 fields scouted were recorded using a disease threshold of $10 \%$ and a probability threshold for action of $35 \%$. In 2017, 31 successes out of 38 fields scouted were recorded using the DI10 threshold and probability thresholds of 35 or $40 \%$. Both type 1 and 2 errors were observed; however, the majority of the errors were due to model underprediction (type 2 error).

In 2017 research trials, model predictions during the soybean flowering period explained end-of-season SSR in $83.3 \%$ of examined cases, using all probability and disease thresholds (Table 8).

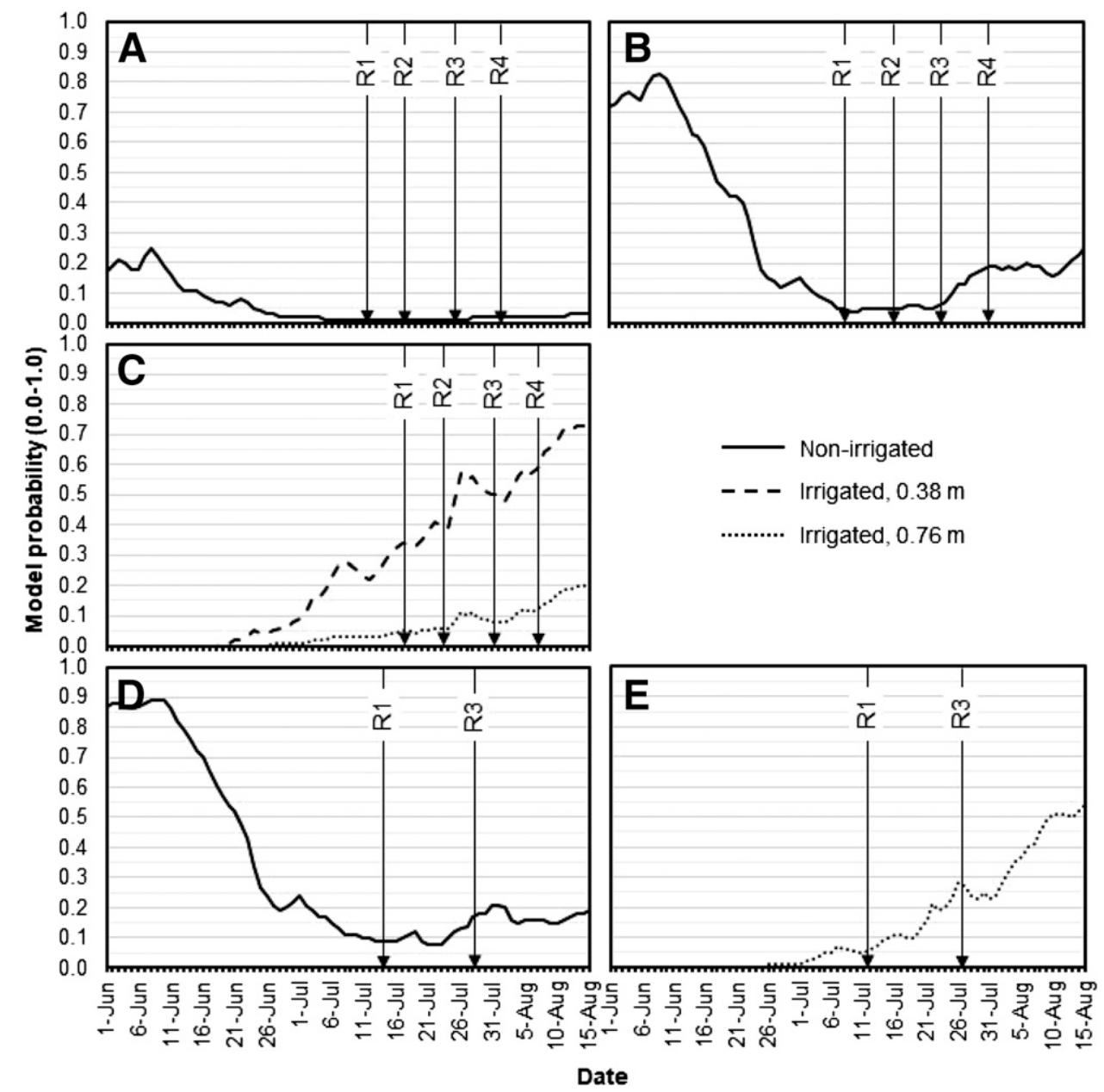

Fig. 1. Model validations conducted in research trials in 2017 located in A, Nashua and B, Manilla, IA; C, Montcalm, MI; and D, Arlington and E, Hancock, WI. The solid line indicates model probabilities for nonirrigated soybean fields; the logit was calculated using equation 1. The dashed line indicates model probabilities for irrigated soybean fields at a narrow, 0.38-m row spacing; the logit was calculated using equation 2 , where the row variable is equal to 0 . The dotted line indicates model probabilities for irrigated soybean fields at a wide, $0.76-\mathrm{m}$ row spacing; the logit was calculated using equation 2, where the row variable is equal to 1 . All probabilities were calculated from the logit using equation 3 . All weather data used in these validations were provided by the Integrated Pest Information Platform for Extension and Education weather network and were generated using GPS coordinates for each location. Dates of the growth stages R1 (beginning flower), R2 (full flower), R3 (beginning pod), and R4 (full pod), often where fungicide treatments were applied in efficacy trials, are indicated by the vertical labeled arrows. 
In commercial fields, models accurately explained SSR levels in $81.7 \%$ of cases examined using a $10 \%$ disease threshold and $35 \%$ probability threshold for action. Using a 5\% disease threshold and the probability threshold of $35 \%$, models accurately predicted SSR in $76.7 \%$ of commercial field cases. Across all years and locations (commercial and research), apothecial models accurately predicted SSR in $81.8 \%$ of the cases examined when using the $10 \%$ DI threshold and $35 \%$ probability threshold for action. Using a $40 \%$ action threshold resulted in accurately predicting SSR $78.8 \%$ of the time. Using a 5\% DI threshold and $35 \%$ probability threshold for action resulted in models predicting SSR $77.3 \%$ of the time across all locations.

Correlations between Dark Sky, on-site, and RTMA weather data. Dark Sky weather data were correlated with both on-site and gridded RTMA data (Table 9). For AT and RH, Pearson ( $r$ ) and concordance $\left(r_{c}\right)$ coefficients were $\geq 0.91$ compared with on-site data and $\geq 0.97$ compared with RTMA data (used to develop the apothecial models). For WS, $r$ was 0.85 or 0.87 when compared with on-site or RTMA data, respectively. The concordance analyses indicated that Dark Sky WS $r_{c}$ was 0.72 for on-site data or 0.86 for RTMA data. Dark Sky data had bias coefficients of $0.069( \pm 0.786)$ for WS, 0.642
$( \pm 3.897)$ for $\mathrm{RH}$, and $0.116( \pm 0.749)$ for AT when compared with RTMA data. These bias coefficients were used to modify the model equations for nonirrigated fields:

$$
\begin{aligned}
\operatorname{Logit}(\mu)= & -0.47\left(\operatorname{MaxAT}_{30 M A}+0.865\right)-1.01\left(\operatorname{MaxWS}_{30 M A}+\right. \\
& 0.855)+16.65
\end{aligned}
$$

and irrigated fields:

$$
\begin{aligned}
\operatorname{Logit}(\mu)= & -2.38(\text { Row })+0.65\left(\operatorname{MaxAT}_{30 M A}+0.865\right)+ \\
& 0.38\left(\text { MaxRH }_{30 M A}+4.539\right)-52.65
\end{aligned}
$$

These model equations were then used in equation 3 to generate probabilities for tests of Dark Sky-driven model accuracy at 2017 commercial locations.

Model accuracy using Dark Sky weather data. In the subset of commercial field sites used for validation of model prediction, model accuracy was $87.9 \%$ when Dark Sky-driven (bias-corrected) model predictions were used, with a $10 \%$ DI threshold and a $40 \%$ probabil-

\begin{tabular}{|c|c|c|c|c|c|c|c|c|c|}
\hline \multirow[b]{2}{*}{ Treatment } & \multirow[b]{2}{*}{ Product } & \multirow[b]{2}{*}{ Rate/ha } & \multirow[b]{2}{*}{ Time $^{y}$} & \multicolumn{3}{|c|}{ 0.76-m spacing } & \multicolumn{3}{|c|}{ 0.38-m spacing } \\
\hline & & & & DI (\%) & DIX (\%) & $\overline{\text { Yld (kg/ha) }}$ & DI (\%) & DIX (\%) & $\overline{\text { Yld (kg/ha) }}$ \\
\hline 1 & Nontreated & $\ldots$ & $\ldots$ & 42.0 & 31.1 & $3,284.4 \mathrm{~cd}$ & 80.0 & $70.3 \mathrm{a}-\mathrm{d}$ & $4,641.0$ \\
\hline 2 & Cobra & $438.5 \mathrm{ml}$ & V5 & 46.7 & 30.4 & $3,352.8 \mathrm{~cd}$ & 95.8 & $84.7 \mathrm{ab}$ & $4,159.5$ \\
\hline 3 & Endura & $560.4 \mathrm{~g}$ & $\mathrm{R} 1$ & 52.7 & 35.6 & $3,723.2 \mathrm{bc}$ & 75.8 & 62.2 bde & $2,713.3$ \\
\hline 4 & Endura & $560.4 \mathrm{~g}$ & $\mathrm{R} 2$ & 64.7 & 32.2 & $4,412.5 \mathrm{a}$ & 56.7 & $43.3 \mathrm{e}$ & $4,426.6$ \\
\hline 5 & Endura & $560.4 \mathrm{~g}$ & R3 & 68.0 & 38.0 & $4,260.7 \mathrm{ab}$ & 65.8 & $50.8 \mathrm{de}$ & $4,668.8$ \\
\hline 6 & Endura & $560.4 \mathrm{~g}$ & $\mathrm{R} 4$ & 63.3 & 34.7 & $4,238.3 \mathrm{ab}$ & 67.5 & $56.1 \mathrm{cde}$ & $2,948.4$ \\
\hline 7 & Aproach & $657.7 \mathrm{ml}$ & $\mathrm{R} 1$ & 50.0 & 32.9 & $3,078.7 \mathrm{~cd}$ & 95.8 & $87.8 \mathrm{a}$ & $4,183.0$ \\
\hline 8 & Aproach & $657.7 \mathrm{ml}$ & $\mathrm{R} 2$ & 44.0 & 33.3 & $3,317.7 \mathrm{~cd}$ & 90.0 & $80.8 \mathrm{abc}$ & $3,933.8$ \\
\hline 9 & Aproach & $657.7 \mathrm{ml}$ & R3 & 55.3 & 32.9 & $3,750.8 \mathrm{abc}$ & 67.5 & $58.1 \mathrm{cde}$ & $4,333.0$ \\
\hline \multirow[t]{2}{*}{10} & Aproach & $657.7 \mathrm{ml}$ & $\mathrm{R} 1 \mathrm{fb}$ & 50.7 & 31.1 & $3,698.8 \mathrm{bc}$ & 70.0 & $55.8 \mathrm{cde}$ & $4,472.1$ \\
\hline & Aproach & $657.7 \mathrm{ml}$ & R3 & $\ldots$ & $\ldots$ & $\ldots$ & $\ldots$ & $\ldots$ & $\ldots$ \\
\hline \multirow[t]{2}{*}{11} & Cobra & $438.5 \mathrm{ml}$ & $\mathrm{V} 5 \mathrm{fb}$ & 56.7 & 31.8 & $2,965.7 \mathrm{~d}$ & 76.7 & $63.3 \mathrm{a}-\mathrm{e}$ & $5,306.0$ \\
\hline & Aproach & $657.7 \mathrm{ml}$ & R1 & $\ldots$ & $\ldots$ & $\ldots$ & $\ldots$ & $\ldots$ & $\ldots$ \\
\hline$F$ & $\ldots$ & $\ldots$ & $\ldots$ & 0.99 & 0.30 & 4.28 & 1.91 & 2.69 & 1.71 \\
\hline$P$ value & $\cdots$ & $\cdots$ & $\cdots$ & 0.47 & 0.98 & $<0.01$ & 0.08 & 0.02 & 0.13 \\
\hline
\end{tabular}
ity threshold to explain SSR in the cases examined (Table 10). Of the

Table 5. Validation of various fungicide products and application timings at 0.76 - and $0.38-\mathrm{m}$ row spacings, evaluated using disease incidence (DI), disease severity index (DIX), and yield (Yld), in Montcalm, MI 2017x

${ }^{x}$ Means followed by the same letter, in each column, were not significantly different based on Fisher's least significant difference at the $\alpha=0.05$ significance level.

y Application timing. Sequential application timings were made in some instances and are indicated by $\mathrm{fb}=$ followed by

\begin{tabular}{|c|c|c|c|c|c|c|c|}
\hline Treatment & Product & Threshold $(\%)^{\mathrm{w}}$ & Rate/ha & Application timing $x$ & True DI $(\%)^{\mathbf{y}}$ & DIX (\%) & Yield (kg/ha) \\
\hline 1 & Nontreated & $\ldots$ & $\ldots$ & $\ldots$ & 2.0 & 1.5 & $4,254.6$ \\
\hline \multirow[t]{2}{*}{2} & Aproach & - & $657.7 \mathrm{ml}$ & $\mathrm{R} 1$ & 1.0 & 0.8 & $4,270.7$ \\
\hline & Aproach & - & $657.7 \mathrm{ml}$ & R3 & $\ldots$ & $\ldots$ & $\ldots$ \\
\hline 3 & Endura & - & $560.4 \mathrm{~g}$ & R1 & 0.0 & 0.0 & $4,514.5$ \\
\hline \multirow[t]{2}{*}{4} & Aproach & 15 & $657.7 \mathrm{ml}$ & $\mathrm{R} 1 \mathrm{fb}$ & 2.5 & 1.8 & $4,291.7$ \\
\hline & Aproach & 15 & $657.7 \mathrm{ml}$ & R3 & $\ldots$ & $\ldots$ & $\ldots$ \\
\hline 5 & Aproach & 30 & $657.7 \mathrm{ml}$ & $\ldots$ & 2.5 & 1.4 & $3,888.1$ \\
\hline \multirow[t]{2}{*}{6} & Endura & 15 & $560.4 \mathrm{~g}$ & $\mathrm{R} 1 \mathrm{fb}$ & 0.2 & 0.1 & $4,557.3$ \\
\hline & Endura & 15 & $560.4 \mathrm{~g}$ & R3 & $\ldots$ & $\ldots$ & $\ldots$ \\
\hline 7 & Endura & 30 & $560.4 \mathrm{~g}$ & $\ldots$ & 0.7 & 0.7 & $4,164.9$ \\
\hline$F$ & $\ldots$ & $\ldots$ & $\ldots$ & $\ldots$ & 0.85 & 0.71 & 0.99 \\
\hline$P$ value ${ }^{\mathrm{z}}$ & $\ldots$ & $\ldots$ & $\ldots$ & $\ldots$ & 0.55 & 0.65 & 0.46 \\
\hline
\end{tabular}

${ }^{\mathrm{z}}$ Significance level: $\alpha=0.05$.

Table 6. Validation of various fungicide products and applications timings evaluated using true disease incidence (DI), disease severity index (DIX), and yield in Arlington, WI 2017

${ }^{w}$ Phenology-based fungicide programs were compared with programs applied between the R1 and R3 growth stages when risk was above threshold 1 (equal to

$15 \%$ ) or threshold 2 (equal to $30 \%$ ). In some cases, low predicted risk resulted in no applications, designated by the symbol -.

x Sequential application timings were made in some instances and are indicated by $\mathrm{fb}=$ followed by.

y True DI was calculated using the number of symptomatic plants in the center two rows, divided by the total stand count of the center two rows, and multiplied by 100.

z Significance level: $\alpha=0.05$. 
four model failures at this threshold, type 1 and 2 errors occurred equally. At a $5 \%$ DI threshold, a $40 \%$ probability threshold for action was again most accurate, with models explaining SSR at an $81.8 \%$ success rate. Use of a 30 or $35 \%$ probability threshold at either disease threshold resulted in $<70 \%$ model accuracy.

\section{Discussion}

Extensive validation of two weather-based models for S. sclerotiorum apothecial presence indicated that these models result in highly accurate $(81.8 \%)$ predictions of SSR in both research trials and commercial fields. The later application timings of fungicide treatments (R2 to R4) were most effective in Michigan. The corresponding model-predicted probability in fields with $0.38-\mathrm{m}$ spacing was greater than 35 and $40 \%$ after R1 and before R2. In all three nonirrigated research sites, the model-predicted probability was below 35 and $40 \%$ during the R1 to R3 period and also had correspondingly low levels of observed SSR. The 35 and $40 \%$ probability thresholds for action repeatedly resulted in the greatest accuracy for predicting SSR whether a 5 or $10 \%$ disease threshold was used. The model accuracies (Table 8) generated from research and commercial sites confirm that these are appropriate action thresholds for SSR management. However, reasonable control was achieved when this disease threshold was used to determine accuracy in nonirrigated and irrigated, 0.38-m spacing environments. Most of the sites used in these validations were nonirrigated, dryland fields that were representative for this growing region.

However, the irrigated sites at $0.76-\mathrm{m}$ row spacing (Fig. $1 \mathrm{C}$ and $\mathrm{E}$ ) were not predicted to have probability levels above the action thresholds ( 35 or $40 \%$ ). If a probability threshold of $10 \%$ was used in these situations, then the model predictions would have resulted in appropriately timed fungicide applications for SSR management. Based on the results presented in these studies, the irrigated model at the wider row spacing should be adjusted using lower probability thresholds for effective SSR management. Further validation of these models should be conducted in locations where irrigation is a prevalent management practice in soybean.

Model predictions of low probability for apothecial presence during the flowering period at fungicide evaluation sites in Iowa and Arlington, WI helped to explain the low levels of disease observed at these locations. Low levels of SSR ultimately contributed to the inability to detect differences between the different fungicide treatments and timings. However, with low SSR incidence and severity and little yield impact, the low probability estimates calculated by the model would have prevented the application of costly and unnecessary fungicide programs (approximately US\$115 to $136 \mathrm{ha}^{-1}$ for an effective SSR fungicide program; Anonymous, personal communication).

Additionally, the validation conducted in Arlington suggested that boscalid may be more effective than picoxystrobin, perhaps due to longer-lasting residual activity, despite having similar modes of action (FRAC 2018). Both fungicides inhibit fungal respiration; however, boscalid inhibits a different complex earlier in the fungal respiration cycle. We speculate that the inhibition of a different complex may increase the efficacy of this active ingredient. This is further substantiated in that registrants of these products recommend different frequencies of application to ensure protection. At the standard $560.4 \mathrm{~g} / \mathrm{ha}$ rate of boscalid, one application at the $\mathrm{R} 1$ growth stage is recommended. However, picoxystrobin applied at $657.7 \mathrm{ml} / \mathrm{ha}$ is recommended to be applied at $\mathrm{R} 1$ and at again at the R3 growth stage of soybean to ensure complete protection during the critical infection period. Picoxystrobin is also at high risk for fungicide resistance development whereas boscalid is only at medium to high risk (FRAC 2018). Resistance to either of these active ingredients has not yet been identified in natural $S$. sclerotiorum populations.

The site in Hancock, WI had higher disease pressure; however, no differences in treatments were detected at this location either. Only picoxystrobin was applied at the Hancock site, and similar effects of this active ingredient observed in the Arlington trial could explain the lack of efficacy at this location. Probability of apothecial presence was predicted to be greatest at and after the R3 growth stage (Fig. 1). The R3 application of picoxystrobin may not have provided enough protection for the extended risk period at the end of the flowering period. In Michigan research trials (Table 5), where the risk was greatest after R2, the boscalid applications between R2 and R4 were most effective. The soybean varieties typically grown in the Midwest are indeterminate, with flowering occurring over a 4-week period (Fehr et al. 1971). Although the R1 to R3 period typically designates the flowering period, which is usually approximately 14 days in this region (Table 1), some flowers may be present and become infected after this window if risk remains high. In the Midwest, the soybean SSR risk window may need reevaluation to include the R4 growth stage for adequate SSR management.

Typically, SSR management requires one or two fungicide applications during the R1 to R3 growth period. These results, however,

Table 8. Accuracy of apothecial model predictions from validations conducted in research trials or commercial fields, 2016 and 2017

\begin{tabular}{|c|c|c|c|c|c|c|c|}
\hline \multirow[b]{3}{*}{ Accuracy (\%) } & \multirow[b]{3}{*}{$N^{z}$} & \multicolumn{6}{|c|}{ Success or failure ${ }^{y}$} \\
\hline & & \multicolumn{3}{|c|}{ DI 5\% } & \multicolumn{3}{|c|}{ DI $10 \%$} \\
\hline & & 30 & 35 & 40 & 30 & 35 & 40 \\
\hline Research trials, 2017 & 6 & 83.3 & 83.3 & 83.3 & 83.3 & 83.3 & 83.3 \\
\hline Commercial fields, 2016 and 2017 & 60 & 63.3 & 76.7 & 73.3 & 68.3 & 81.7 & 78.3 \\
\hline Total & 66 & 65.2 & 77.3 & 74.2 & 69.7 & 81.8 & 78.8 \\
\hline \multicolumn{8}{|c|}{$\begin{array}{l}\text { y Binary model successes (1) or failures ( } 0 \text { ) for each model action threshold } \\
\text { (30, 35, or } 40 \% \text { ) using disease incidence (DI) thresholds of } 5 \text { or } 10 \% \text { were } \\
\text { used to determine model accuracy across all locations and years. The number } \\
\text { of successes was divided by the total number of field validations and multi- } \\
\text { plied by } 100 \text {. }\end{array}$} \\
\hline
\end{tabular}

Table 7. Validation of various fungicide products and application timings evaluated using true disease incidence (DI), disease severity index (DIX), and yield in Hancock, WI 2017

\begin{tabular}{|c|c|c|c|c|c|c|c|}
\hline Treatment & Product & Threshold $(\%)^{\mathrm{w}}$ & Rate/ha & Application timing $x$ & True DI $(\%)^{\mathbf{y}}$ & DIX (\%) & Yield (kg/ha) \\
\hline 1 & Nontreated & $\ldots$ & . & $\ldots$ & 17.7 & 17.6 & $3,099.3$ \\
\hline \multirow[t]{2}{*}{2} & Aproach & - & $657.7 \mathrm{ml}$ & $\mathrm{R} 1 \mathrm{fb}$ & 16.7 & 16.4 & $3,602.5$ \\
\hline & Aproach & - & $657.7 \mathrm{ml}$ & R3 & $\ldots$ & $\ldots$ & $\ldots$ \\
\hline \multirow[t]{2}{*}{3} & Aproach & 15 & $657.7 \mathrm{ml}$ & $\mathrm{R} 1 \mathrm{fb}$ & 14.8 & 14.7 & $3,337.9$ \\
\hline & Aproach & 15 & $657.7 \mathrm{ml}$ & $\mathrm{R} 3$ & $\ldots$ & $\ldots$ & $\ldots$ \\
\hline 4 & Aproach & 30 & $657.7 \mathrm{ml}$ & R3 & 20.6 & 20.6 & $3,627.0$ \\
\hline$F$ & $\ldots$ & $\ldots$ & $\ldots$ & $\ldots$ & 0.37 & 0.41 & 2.23 \\
\hline$P$ value ${ }^{2}$ & $\ldots$ & $\ldots$ & $\cdots$ & $\ldots$ & 0.77 & 0.75 & 0.15 \\
\hline
\end{tabular}

w Phenology-based fungicide programs were compared with programs applied between the R1 and R3 growth stages when risk was above threshold 1 (equal to

$15 \%$ ) or threshold 2 (equal to $30 \%$ ). In some cases, low predicted risk resulted in no applications, designated by the symbol -.

x Sequential application timings were made in some instances and are indicated by $\mathrm{fb}=$ followed by.

y True DI was calculated using the number of symptomatic plants in the center two rows, divided by the total stand count of the center two rows, and multiplied by 100 .

z Significance level: $\alpha=0.05$. 
indicate that the prediction models validated here can both reduce unnecessary fungicide input and improve application timing during the flowering period. For instance, in the areas of high disease pressure included in this study, a two-spray program may have been most effectively applied at the R2 and R4 growth stages, as estimated by the models. Using the determined probability action thresholds, these models could be extremely effective and impactful in SSR management. Moreover, an accessible smartphone application for farmers

Table 9. Bias, Pearson, and concordance coefficients with corresponding standard deviations (SD) or 95\% confidence intervals (CI) for correlation analyses of Dark Sky weather data and on-site Campbell Scientific weather station or gridded real-time mesoscale analysis (RTMA) data (sourced iPiPE)

\begin{tabular}{|c|c|c|c|c|c|}
\hline \multirow[b]{2}{*}{ Weather variable } & \multirow{2}{*}{$\frac{\text { Bias }^{\mathrm{z}}}{\text { Coefficient } \pm \text { SD }}$} & \multicolumn{2}{|c|}{ Pearson correlation } & \multicolumn{2}{|c|}{ Concordance correlation } \\
\hline & & Coefficient, $r$ & $95 \% \mathrm{CI}$ & Coefficient, $r_{c}$ & $95 \% \mathrm{CI}$ \\
\hline \multicolumn{6}{|c|}{ Campbell Weather Station } \\
\hline Air temperature & $-0.633 \pm 0.965$ & 0.98 & $(0.979,0.981)$ & 0.97 & $(0.970,0.973)$ \\
\hline Relative humidity & $4.312 \pm 5.140$ & 0.94 & $(0.943,0.949)$ & 0.91 & $(0.907,0.912)$ \\
\hline Wind speed & $-0.814 \pm 0.790$ & 0.85 & $(0.834,0.856)$ & 0.72 & $(0.704,0.735)$ \\
\hline \multicolumn{6}{|l|}{ Gridded RTMA data } \\
\hline Air temperature & $0.116 \pm 0.749$ & 0.99 & $(0.988,0.989)$ & 0.99 & $(0.987,0.989)$ \\
\hline Relative humidity & $0.642 \pm 3.897$ & 0.97 & $(0.969,0.972)$ & 0.97 & $(0.968,0.971)$ \\
\hline Wind speed & $0.069 \pm 0.786$ & 0.87 & $(0.861,0.875)$ & 0.86 & $(0.857,0.871)$ \\
\hline
\end{tabular}

${ }^{\mathrm{z}}$ Bias coefficients were calculated from the mean difference between hourly Dark Sky data and on-site Campbell Scientific or gridded RTMA data; bias coefficient $=$ Dark Sky data - onsite or RTMA data. iPiPE $=$ Integrated Pest Information Platform for Extension and Education.

Table 10. Validations of apothecial risk models in commercial farmers' fields, including information on row spacing, irrigation status, fungicide applications, apothecial presence or absence (Apo), and mean disease incidence (DI) using Dark Sky weather data in 2017

\begin{tabular}{|c|c|c|c|c|c|c|c|c|c|c|c|c|}
\hline \multirow[b]{2}{*}{ Field ID } & \multirow[b]{2}{*}{ DI5 $^{y}$} & \multirow[b]{2}{*}{ DI10 $^{z}$} & \multicolumn{3}{|c|}{$\begin{array}{c}\text { Risk } \geq \text { threshold } \\
(\%) \text { between R1 } \\
\text { and } \text { R3 }^{v}\end{array}$} & \multicolumn{3}{|c|}{$\begin{array}{l}\text { Success or failure } \\
(\text { DI 5\%) }\end{array}$} & \multicolumn{3}{|c|}{$\begin{array}{l}\text { Success or failure } \\
(\text { DI 10\%) }\end{array}$} & \multirow{2}{*}{$\frac{\text { Type } 1 \text { or } 2 \text { error }(\text { DI10 })^{x}}{40}$} \\
\hline & & & 30 & 35 & 40 & 30 & 35 & 40 & 30 & 35 & 40 & \\
\hline$\overline{\mathrm{C} 17-\mathrm{W} 1}$ & 0 & 0 & 0 & 0 & 0 & 1 & 1 & 1 & 1 & 1 & 1 & 0 \\
\hline C17-W2 & 0 & 0 & 0 & 0 & 0 & 1 & 1 & 1 & 1 & 1 & 1 & 0 \\
\hline C17-W3 & 0 & 0 & 0 & 0 & 0 & 1 & 1 & 1 & 1 & 1 & 1 & 0 \\
\hline C17-W4 & 0 & 0 & 0 & 0 & 0 & 1 & 1 & 1 & 1 & 1 & 1 & 0 \\
\hline C17-W5 & 0 & 0 & 0 & 0 & 0 & 1 & 1 & 1 & 1 & 1 & 1 & 0 \\
\hline C17-W6 & 0 & 0 & 0 & 0 & 0 & 1 & 1 & 1 & 1 & 1 & 1 & 0 \\
\hline C17-W7 & 0 & 0 & 0 & 0 & 0 & 1 & 1 & 1 & 1 & 1 & 1 & 0 \\
\hline C17-W8 & 0 & 0 & 0 & 0 & 0 & 1 & 1 & 1 & 1 & 1 & 1 & 0 \\
\hline C17-W9 & 0 & 0 & 0 & 0 & 0 & 1 & 1 & 1 & 1 & 1 & 1 & 0 \\
\hline C17-W10 & 0 & 0 & 0 & 0 & 0 & 1 & 1 & 1 & 1 & 1 & 1 & 0 \\
\hline C17-W11 & 0 & 0 & 0 & 0 & 0 & 1 & 1 & 1 & 1 & 1 & 1 & 0 \\
\hline C17-W12 & 0 & 0 & 1 & 0 & 0 & 0 & 1 & 1 & 0 & 1 & 1 & 0 \\
\hline C17-W13 & 1 & 0 & 1 & 1 & 0 & 1 & 1 & 0 & 0 & 0 & 1 & 0 \\
\hline C17-W14 & 0 & 0 & 1 & 1 & 1 & 0 & 0 & 0 & 0 & 0 & 0 & 1 \\
\hline C17-W15 & 1 & 1 & 1 & 1 & 1 & 1 & 1 & 1 & 1 & 1 & 1 & 0 \\
\hline C17-W16 & 1 & 1 & 1 & 1 & 1 & 1 & 1 & 1 & 1 & 1 & 1 & 0 \\
\hline C17-W17 & 1 & 1 & 1 & 1 & 1 & 1 & 1 & 1 & 1 & 1 & 1 & 0 \\
\hline C17-W18 & 0 & 0 & 1 & 1 & 0 & 0 & 0 & 1 & 0 & 0 & 1 & 0 \\
\hline C17-W19 & 0 & 0 & 1 & 1 & 0 & 0 & 0 & 1 & 0 & 0 & 1 & 0 \\
\hline C17-W20 & 0 & 0 & 1 & 1 & 1 & 0 & 0 & 0 & 0 & 0 & 0 & 1 \\
\hline C17-W21 & 1 & 1 & 1 & 1 & 1 & 1 & 1 & 1 & 1 & 1 & 1 & 0 \\
\hline C17-W22 & 0 & 0 & 1 & 1 & 0 & 0 & 0 & 1 & 0 & 0 & 1 & 0 \\
\hline C17-W23 & 0 & 0 & 1 & 1 & 0 & 0 & 0 & 1 & 0 & 0 & 1 & 0 \\
\hline C17-W24 & 0 & 0 & 1 & 1 & 0 & 0 & 0 & 1 & 0 & 0 & 1 & 0 \\
\hline C17-W25 & 0 & 0 & 0 & 0 & 0 & 1 & 1 & 1 & 1 & 1 & 1 & 0 \\
\hline C17-W26 & 0 & 0 & 0 & 0 & 0 & 1 & 1 & 1 & 1 & 1 & 1 & 0 \\
\hline C17-W27 & 0 & 0 & 0 & 0 & 0 & 1 & 1 & 1 & 1 & 1 & 1 & 0 \\
\hline C17-W28 & 0 & 0 & 0 & 0 & 0 & 1 & 1 & 1 & 1 & 1 & 1 & 0 \\
\hline C17-W29 & 1 & 0 & 0 & 0 & 0 & 0 & 0 & 0 & 1 & 1 & 1 & 0 \\
\hline C17-W30 & 1 & 1 & 0 & 0 & 0 & 0 & 0 & 0 & 0 & 0 & 0 & 2 \\
\hline C17-W31 & 0 & 0 & 0 & 0 & 0 & 1 & 1 & 1 & 1 & 1 & 1 & 0 \\
\hline C17-W32 & 0 & 0 & 0 & 0 & 0 & 1 & 1 & 1 & 1 & 1 & 1 & 0 \\
\hline C17-W33 & 1 & 1 & 0 & 0 & 0 & 0 & 0 & 0 & 0 & 0 & 0 & 2 \\
\hline Accuracy $(\%)$ & $\ldots$ & $\ldots$ & $\ldots$ & $\ldots$ & $\ldots$ & 66.7 & 69.7 & 81.8 & 66.7 & 69.7 & 87.9 & $50 / 50$ \\
\hline
\end{tabular}

${ }^{\mathrm{v}}$ If the modeled apothecial risk (equations 3,4 , and 5) during the R1 to R3 growth stages was predicted above the indicated probability thresholds (30, 35, or $40 \%$ ), the observation was given a 1. If the apothecial risk did not reach above these thresholds, then the observation was given a 0 .

${ }^{\mathrm{w}}$ If the binary risk predictions matched the corresponding binary disease observations at 5 or $10 \%$, then the validation location was determined a success (1). If the risk predictions did not match disease observations, then the validation was determined a failure (0). Successes and failures were used to calculate model accuracy across all locations.

${ }^{x}$ If the validation was determined a failure and disease was under the disease threshold (5 or 10\%) (i.e., the model overpredicted risk in that location), then the error was considered type 1 (1). If the failure occurred in an area where disease was above threshold (5 or 10\%) (i.e., the model underpredicted risk in the area), then the error was considered type 2 (2). Of the cases examined, 50\% of the errors were type 1 and $50 \%$ were type 2.

${ }^{y}$ If the mean DI was above $5 \%$, then DI5 was given a 1 . If not, then the DI5 was 0.

${ }^{\mathrm{z}}$ If the mean DI was above $10 \%$, then DI10 was given a 1. If not, then the DI10 was 0. 
would be most useful in implementing these models for SSR management.

Unfortunately, the RTMA data, although available as regional maps, are not easily available for site-specific smartphone application development. The Dark Sky data, however, are available through an application programming interface (Dark Sky Company). Therefore, these data were evaluated for site-specific weather and model predictions. As shown, the Dark Sky data were strongly correlated to both on-site and RTMA weather data. Additionally, these data, when corrected with biases, provided accurate model predictions in 2017 Wisconsin commercial sites, with an 81.8 or $87.9 \%$ accuracy at a probability threshold for action of $40 \%$. These results suggest that, although the Dark Sky may be an acceptable surrogate for use in smartphone applications of these models, probability thresholds for action may require a slight adjustment to correct for inflated model predictions.

Based on the results presented here, the nonirrigated and irrigated $0.38-\mathrm{m}$ spacing models should be used with a $35 \%$ probability action threshold. Irrigated, 0.76-m spacing environments should use a $10 \%$ probability action threshold. When flowers are present on soybean (potentially R1 to R4), fungicide applications should be applied according to these action thresholds for effective SSR management. Furthermore, Dark Sky data may be an acceptable surrogate for RTMA data by using adjusted probability thresholds for model implementation. If Dark Sky data are used, action thresholds of 40 and 15\% may be appropriate for nonirrigated or narrow-row, irrigated environments and irrigated wide-row environments, respectively.

\section{Acknowledgments}

We thank our undergraduate research assistants for their contributions to the intensive field studies conducted in this work: in Wisconsin, T. Blackwell, P. Buethe, C. Chadwick, C. Emrick, D. Holtz, B. Peppard, N. Phillipps, T. Rittmeyer, and M. Young; in Michigan, J. Bunner, Z. Sundin, C. Meredith, and K. Naasko; in Nebraska, N. Arneson; and in Iowa, R. Kempker; iPiPE personnel for their continued technical support in using modeled weather data in our apothecial prediction model; and J. Schlegel at ZedX, Inc. for assistance in acquiring data.

\section{Literature Cited}

Abawi, G. S., and Grogan, R. G. 1975. Source of primary inoculum and effects of temperature and moisture on infection of beans by Whetzelinia sclerotiorum. Phytopathology 65:300-309.

Allen, T. W., Bradley, C. A., Sisson, A. J., Byamulama, E., Chilvers, M. I., Coker, C. M., Collins, A. A., Damicone, J. P., Dorrance, A. E., Dufault, N. S., Esker, P. D., Faske, T. R., Giesler, L. J., Grybauskas, A. P., Hershman, D. E., Hollier, C. A., Isakeit, T., Jardine, D. J., Kemerait, R. C., Kleczewski, N. M., Koenning, S. R., Kurle, J. E., Malvick, D. K., Markell, S. G., Mehl, H. L., Mueller, D. S., Mueller, J. D., Mulrooney, R. P., Nelson, B. D., Newman, M. A., Osborne, L., Overstreet, C., Padgett, G. B., Phipps, P. M., Price, P. P., Sikora, E. J., Smith, D. L., Spurlock, T. N., Tande, C. A., Tenuta, A. U., Wise, K. A., Wrather, J. A., and Young-Kelly, H. 2017. Soybean yield loss estimates due to diseases in the United States and Ontario, Canada, from 2010 to 2014. Plant Health Prog. 18:19-27.

Benjamin, S., Brown, J., and Manikin, G. 2007. The RTMA background-Hourly downscaling of RUC data to 5-km detail. Online publication. 22nd Conf. Weather Anal. Forecasting/18th Conf. Numerical Weather Prediction. http:// ams.confex.com/ams/22WAF18NWP/techprogram/paper_124825.htm

Bondalapati, K. D., and Stein, J. M. 2010. Validation of barley DON risk prediction model. Page 71 in: Proc. 2010 Natl. Fusarium Head Blight Forum, Milwaukee, WI. University of Kentucky.

Charney, J. J., Service, U. F., and Kiefer, M. T. 2013. An investigation of the differences between Real Time Mesoscale Analysis and observed meteorological conditions at RAWS stations in the northeast United States. Online publication. JFSP Res. Proj. Rep. https://digitalcommons.unl.edu/jfspresearch/25

Clarkson, J. P., Fawcett, L., Anthony, S. G., and Young, C. 2014. A model for Sclerotinia sclerotiorum infection and disease development in lettuce, based on the effects of temperature, relative humidity and ascospore density. PLoS One 9:e94049.

Fall, M. L., Boyse, J. F., Wang, D., Willbur, J., Smith, D. L., and Chilvers, M. 2018. Case study of an epidemiological approach dissecting historical soybean Sclerotinia stem rot observations and identifying environmental predictors of epidemics and yield loss. Phytopathology 108:469-478.

Fehr, W. R., Caviness, C. E., Burmood, D. T., and Pennington, J. S. 1971. Stage of development descriptions for soybeans, Glycine $\max ($ L.) Merill. Crop Sci. 11: 929-931.

Foster, A. J., Kora, C., McDonald, M. R., and Boland, G. J. 2011. Development and validation of a disease forecast model for Sclerotinia rot of carrot. Can. J. Plant Pathol. 33:187-201.

FRAC. 2018. Fungicide Resistance Action Committee Code List 2017: Fungicides Sorted by Mode of Action. Online publication. http://www.frac.info

Grau, C., Radke, V., and Gillespie, F. 1982. Resistance of soybean cultivars to Sclerotinia sclerotiorum. Plant Dis. 66:506-508

Grau, C. R., and Hartman, G. L. 2015. Sclerotinia stem rot. In: Compendium of Soybean Diseases, 5th ed. G. L. Hartman, J. C. Rupe, E. J. Sikora, L. L. Domier, J. A. Davis, and K. L. Steffey, eds. American Phytopathological Society, St Paul, MN.

Harikrishnan, R., and del Río, L. E. 2008. A logistic regression model for predicting risk of white mold incidence on dry bean in North Dakota. Plant Dis. 92:42-46.

Isard, S. A., Russo, J. M., Magarey, R. D., Golod, J., and Vankirk, J. R. 2015 Integrated pest information platform for extension and education (iPiPE): Progress through sharing. J. Integr. Pest Manage. 6:15.

Lengerich, R. 2017. Concordance correlation coefficient for measuring agreement In: Statistics 509: Design and Analysis of Clinical Trials. The Pennsylvania State University, Eberly College of Science

Lin, L. I. 1989. A concordance correlation coefficient to evaluate reproducibility Biometrics 45:255-268.

Magarey, R. D., Seem, R. C., Russo, J. M., Zack, J. W., Waight, K. T., Travis, J. W., and Oudemans, P. V. 2001. Site-specific weather information without on-site sensors. Plant Dis. 85:1216-1226.

Monsanto. 2017. Soybean Product Library. Online publication. http://www. agseedselect.com/product-library

Peltier, A. J., Bradley, C. A., Chilvers, M. I., Malvick, D. K., Mueller, D. S., Wise, K. A., and Esker, P. D. 2012. Biology, yield loss and control of Sclerotinia stem rot of soybean. J. Integr. Pest Manage. 3:1-7.

Piepho, H.-P. 2004. An algorithm for a letter-based representation of all-pairwise comparisons. J. Comput. Graph. Stat. 13:456-466.

Pioneer. 2017. Soybean Product Information. Online publication. https://ca. pioneer.com/east/en/products/soybeans/

Saharan, G. S., and Mehta, N. 2008. Sclerotinia Diseases of Crop Plants: Biology, Ecology and Disease Management. Springer Netherlands.

Smith, D. L., Hollowell, J. E., Isleib, T. G., and Shew, B. B. 2007. A site-specific, weather-based disease regression model for Sclerotinia blight of peanut. Plant Dis. 91:1436-1444.

Twengström, E., Sigvald, R., Svensson, C., and Yuen, J. 1998. Forecasting Sclerotinia stem rot in spring sown oilseed rape. Crop Prot. 17:405-411.

Wharton, P. S., Kirk, W. W., Baker, K. M., and Duynslager, L. 2008. A web-based interactive system for risk management of potato late blight in Michigan. Comput. Electron. Agric. 61:136-148.

Willbur, J. F., Fall, M. L., Bloomingdale, C. A., Byrne, A. M., Chapman, S. A., Isard, S. A., Magarey, R. D., McCaghey, M. M., Mueller, B. D., Russo, J. M., Schlegel, J., Chilvers, M. I., Mueller, D. S., Kabbage, M., and Smith, D. L. 2018. Weather-based models for assessing the risk of Sclerotinia sclerotiorum apothecial presence in soybean (Glycine max) fields. Plant Dis. 102:73-84

Wrather, A., Shannon, G., Balardin, R., Carregal, L., Escobar, R., Gupta, G. K., Ma, Z., Morel, W., Ploper, D., and Tenuta, A. 2010. Effect of diseases on soybean yield in the top eight producing countries in 2006. Online publication. Plant Health Prog. doi.org/10.1094/PHP-2010-0102-01-RS 